\title{
ROLE OF ETHANOL LOCK THERAPY VS HEPARIN LOCK IN PREVENTING INFECTIONS IN NON-TUNNELED HEMODIALYSIS CATHETERS
}

\author{
Sagar KD Shrestha ${ }^{1}$, K.B. Raut ${ }^{2}$
}

\section{ABSTRACT}

INTRODUCTION: This study aims to determine the rate of catheter related bloodstream infection using intraluminal $70 \%$ ethanol lock 20 min prior to initiation of hemodialysis in comparison with heparin lock and also to study adverse events with the use of locks.

MATERIAL AND METHODS: Out of 196 patients, eligible 128 patients who under went hemodialysis in Tribhuwan University Teaching Hospital, were randomly allocated to 68 jugular catheterization with ethanol lock or heparin lock and 60 femoral catheterization with ethanol lock or heparin lock. 5 patients with jugular catheter with ethanol lock and 3 patients with heparin lock changed center. The major outcomes were catheter-related blood stream infection (CRBSI) or thrombosis or other adverse effects.

RESULTS: According to KDIGO definition of CRBSI, definite CRBSI occurred in 22 (18.33\%) patients in Heparin group, probable CRBSI occurred in 31 (25.83\%) patients in Heparin whereas definite CRBSI occurred in $1(1.38 \%)$ patient in Ethanol group, and possible CRBSI occurred in $18(15.00 \%)$ patients in Ethanol group. Most common organisms isolated were Staphylococcus aureus and Enterococcus faecalis in heparin group. No adverse events occurred in ethanol group.

CONCLUSION: Our study has suggested Ethanol lock therapy is effective in preventing CRBSI as there were fewer CRBSI in ethanol lock in comparision to heparin lock which needs to studied in large population.

\section{KEYWORDS: Ethanol lock therapy, Heparin lock, CRBSI}

1. DM Resident, Department of Nephrology, Tribhuvan University Teaching Hospital, Kathmandu, Nepal

2. Professor, Department of Nephrology, Tribhuvan University Teaching Hospital, Kathmandu, Nepal

For Correspondence

Dr..Sagar KD Shrestha

DM Resident,

Department of Nephrology, Tribhuvan Univerisity Teahing Hospital, Kathmandu, Nepal

E-mail:drshagar@gmail.com 


\section{INTRODUCTION}

Vascular access is the Achilles' heel for patients requiring hemodialysis. ${ }^{1}$ Although the techniques for sustainable vascular access have developed since 1960 after first successful cannulation of blood vessels by Scribner et al. ${ }^{2}$, majority of the ESRD patients initiate renal replacement therapy in the form of hemodialysis (HD) through the nontunneled vascular catheter., $\mathrm{AV}$ fistula is a better vascular access but it needs several weeks to mature and fistula failure ${ }^{5}$ prompts use of non-tunneled vascular catheter as a bridge to hemodialysis. This catheter can be a source of infection if it gets colonized with micro-organism from the exit-site of catheter or through the catheter hub. Bacterial migration through the hub or the exit site and growth on the surface of catheter with biofilm formation occurs within a day of catheter placement. ${ }^{6}$ Catheter related bacteremia often arises from this biofilm which not only leads to complications but also increased morbidity, length of hospitalization, costs and mortality. Systemic antibiotics are of little help in eradicating microorganisms because of their poor penetration in the biofilm..$^{9-8}$ Locking the catheter with a variety of antibiotics ${ }^{9}$ and anticoagulants ${ }^{10}$ have been tried to eradicate organisms from biofilms, but their use have decreased as they have limited spectrum, lead to resistant strains and there is risk of systemic toxicity. ${ }^{11,12}$ Ethanol lock therapy could be an alternative since it is bactericidal and fungicidal and development of resistance is not known. ${ }^{13,14}$ Furthermore, ethanol possesses intrinsic anticoagulant activity, as evidenced by the use of ethanol to restore catheter patency. ${ }^{15} \mathrm{It}$ is cost-effective. So there are studies when catheter salvage has been tried without complications ${ }^{16}$ or with ethanol lock therapy. ${ }^{17}$ We studied the effect of ethanol lock therapy in preventing catheter related bloodstream infections in nontunneled temporary vascular catheters among Nepali population, where no previous such studies has been done in our settings.

\section{MATERIAL AND METHODS}

Patients requiring hemodialysis at Tribhuvan University Teaching Hospital (TUTH) in whom a non tunneled hemodialysis catheter is inserted in the femoral vein (in bed bound patients) or in the internal jugular vein (in ambulatory patients) with eligible criteria after informed consent were included in the study from July 2014 till August 2015. Patients were followed from the day of catheter insertion to the day the catheter was no longer needed or any adverse events occurred prompting removal of catheter. The exclusion criteria were Active sepsis at the time of catheter insertion, Patients on intravenous /oral antibiotic therapy, Mechanical complications while inserting central venous catheter (CVC) like hematoma/ pneumothorax.

The patients were randomized to one of two arms: A. Ethanol $(70 \%)[1.4 \mathrm{ml}$ ethanol to be taken in syringe and then $0.6 \mathrm{ml}$ sterile water for injection to be taken in same syringe] $\mathbf{B}$. Heparin $1000 \mathrm{IU} / \mathrm{ml}$ with Normal saline.Each solution to be designated as either solution A or solution B and was prepared in treatment room and served in $3 \mathrm{ml}$ syringes with numbers and label of A or B to HD nurses. The designated lock solution to be used for the entire study or till the CVC is in place. Patient demographic data was collected including age, gender, presence of diabetes mellitus, etiology of renal disease, hemoglobin, serum ferritin, serum albumin at entry into study. Catheter used was Mahurkar double lumen polyurethane hemodialysis catheter in both groups. Outcomes were: I) CRBSI as defined by Kidney Disease Outcomes Quality Initiative (KDOQI) as Definite / Probable / Possible CRBSI (according to KDOQI- Vascular access guideline 2006) ${ }^{18}$ Moreover, for the definite diagnosis of CRBSI, Infectious Disease Society of America (IDSA) ${ }^{19}$ criteria was also included.

Definite bloodstream infection: Isolation of the same organism from a semi-quantitative culture of the catheter tip by roll-plate method ( $>15$ colony-forming units per $5 \mathrm{~cm}$ catheter segment) and from a peripheral or catheter blood sample in a symptomatic patient with no other apparent source of infection. $\left(\mathrm{KDOQI}^{18}\right)$

Probable bloodstream infection: Defervescence of symptoms after antibiotic therapy with or without removal of catheter, in the setting in which blood cultures confirm infection, but catheter tip does not (or catheter tip does, but blood cultures do not) in a symptomatic patient with no other apparent source of infection.

Possible bloodstream infection: Defervescence of symptoms after antibiotic treatment or after removal of catheter in the absence of laboratory confirmation of bloodstream infection in a symptomatic patient with no other apparent source of infection.

Bacteremia was treated by the attending nephrologist using appropriate antibiotics. II) Catheter thrombosis as defined for persistent flow $<200 \mathrm{ml} / \mathrm{min}$ after ruling out mechanical causes and the presence of thrombosis was confirmed by dissecting the catheter on removal. National Kidney Foundation (NKF)-KDOQI ${ }^{18}$ definition for poor flow in tunneled cuffed catheter is blood flow $<300 \mathrm{ml} / \mathrm{min}$. However as the maximum blood flow through the non-tunneled HD catheter is $250-300 \mathrm{ml} / \mathrm{min}$, poor flow was taken as $<200 \mathrm{ml} / \mathrm{min}$. All study patients who had poor flow $(<200 \mathrm{ml} / \mathrm{min})$ were to be evaluated in the following manner-to rule out all the mechanical factors like kink, patient position. If persistent flow $<200 \mathrm{ml} / \mathrm{min}$ despite correcting for mechanical factors, then catheter to be removed and cut to look for presence of thrombus. Femoral access groups were assessed daily for disproportionate swelling of leg with femoral catheter and once it appeared findings of DVT confirmed by colour doppler of leg vesssels to rule out thrombus. Statistical analysis was done using the independent t-test for mean values, Chi-square test and Fisher Exact test were used for the contingency tables with categorical values. The Kaplan-Meier method was adopted for the survival analysis and the comparision of the survival curve was done by using Log Rank (Mantel-Cox) test. SPSS 17 was used for analysis. 


\section{RESUTS}

196 patients were assessed for eligibility, of whom 128 underwent randomization; 30 patients were assigned to receive ethanol in jugular catheters and 30 patients assigned to receive ethanol in femoral catheters as 8 patients changed the center and were excluded from final analysis. Therefore 30 patients in each group were analysed. A total of 13 patients in the heparin group and 12 in the ethanol group with femoral catheters completed the study before the occurrence of CRBSI or thrombosis as either continuous ambulatory peritoneal dialysis (CAPD) was done or Acute Kidney Injury (AKI) recovered or discharged with jugular catheters or AV graft functional. A total of 17 patients in heparin group and 22 patients in ethanol group with jugular catheters completed the study before the occurance of CRBSI or thrombosis as either AV fistula matured or AV graft functional or spontaneous expulsion of catheter occurred or AKI recovered or renal transplant was done. The study groups had similar age sex distribution. The common native kidney disease (NKD) was chronic kidney disease stage-5 (CKD-5) secondary to HTN associated Kidney Disease- 20 in heparin and 25 in ethanol and CKD-5 secondary to Diabetic Nephropathy- 14 in heparin and 18 in ethanol. CKD-5 secondary to IgA nephropathy was NKD among 6 heparin and 4 ethanol groups. The study groups had hemoglobin, albumin, calcium, phosphorous, alkaline phosphatase and transferrin saturation similar with no statistical difference ( $p$-value $>0.05$ ) but heparin group had higher ferritin level in comparision to ethanol group with was statistically significant ( $\mathrm{p}$-value $<0.05$ ). Table 1 . shows among the 72 patients with CRBSI according to KDIGO, definite CRBSI occurred in $22(18.33 \%)$ patients in Heparin group, probable CRBSI occurred in $31(25.83 \%)$ patients in Heparin whereas definite CRBSI occurred in $1(1.38 \%)$ patient in Ethanol group, and possible CRBSI occurred in $18(15.00 \%)$ patients in Ethanol group.

\section{Table 1 : Incidence of CRBSI according to KDIGO}

\begin{tabular}{|l|c|c|c|c|}
\hline \multirow{2}{*}{$\begin{array}{l}\text { Current Venous } \\
\text { Access }\end{array}$} & \multirow{2}{*}{ CRBSI KDIGO } & \multicolumn{2}{|c|}{ Lock solution } & \multirow{2}{*}{ Total } \\
\cline { 3 - 5 } & & Heparin & Ethanol & \\
\hline \multirow{3}{*}{ Femoral } & Definite & 4 & 0 & 4 \\
\cline { 2 - 5 } & Probable & 8 & 0 & 8 \\
\cline { 2 - 5 } & Possible & 16 & 12 & 28 \\
\hline \multirow{3}{*}{ Jugular } & Definite & 6 & 0 & 6 \\
\cline { 2 - 5 } & Probable & 4 & 1 & 5 \\
\cline { 2 - 5 } & Possible & 15 & 6 & 72 \\
\hline
\end{tabular}

Table 2: overall non-elective catheter loss

\begin{tabular}{|l|c|l|l|}
\hline Overall & Heparin (n= 60) & Ethanol (n= 60) & $\begin{array}{l}\text { Chi-square test } \\
\text { p-value }\end{array}$ \\
\hline CRBSI in both accesses & 22 (blood culture positive =10) & 1 (culture positive =1) & \\
\hline $\begin{array}{l}\text { Thrombosis (poor flow) in } \\
\text { jugular catheters }\end{array}$ & 2 & 0 & \\
\hline $\begin{array}{l}\text { Thrombosis (DVT) in } \\
\text { patients with femoral } \\
\text { catheters }\end{array}$ & 4 (blood culture positive =1) & 0 & \\
\hline Total & & & $<0.001$ \\
\hline
\end{tabular}

Table 2 shows incidence of poor flow even after ruling out kink or manipulation occured in left internal jugular vein catheter and one right internal jugular catheter with heparin lock. Four cases of DVT (deep vein thrombosis) in ipsilateral leg with femoral catheter inserted side occurred in heparin locked patients. Total number of catheter lost was more in heparin group which is statistically significant $(\mathrm{P}<0.001)$.

Table 3 shows majority of the organisms isolated were Staphylococcus aureus and Enterococcus faecalis in femoral and jugular accesses with heparin lock. Acinetobacter baumannii-calcoaceticus Complex was isolated in femoral catheter with heparin lock and jugular catheter with ethanol and heparin lock. Citrobater fruendii isolated in femoral catheter with heparin lock. klebsiella pneumonae and pseudomonas aeruginosa isolated in jugular catheter with heparin lock. There were more culture positive in heparin group.

Fig. 1 shows in patients with Femoral access, overall comparison of the survival curve of the catheter with respect to the event of CRBSI shows that the curve of the more events in the heparin group and the survival of the ethanol group was longer as compared to the heparin group. This was statistically significant at $95 \%$ confidence interval with Log-Rank Test pvalue 0.001 which is less than 0.05 .

\section{Table 3 : Pathogens responsible for crbsi}

\begin{tabular}{|c|c|c|c|c|}
\hline \multicolumn{5}{|c|}{ Organism*Lock solution Cross tabulation in femoral } \\
\hline \multirow{2}{*}{\multicolumn{2}{|c|}{ Organism }} & \multicolumn{2}{|c|}{ Lock solution(E=Ethanol/ $\mathbf{H = h e p a r i n )}$} & \multirow[t]{2}{*}{ Total } \\
\hline & & Heparin & Ethanol & \\
\hline \multirow[t]{5}{*}{ Femoral } & Staphylococcus aureus & 3 & 0 & 3 \\
\hline & Enterococcus faecalis & 3 & 0 & 3 \\
\hline & $\begin{array}{l}\text { Acinetobacter baumannii- } \\
\text { calcoaceticus Complex }\end{array}$ & 1 & 0 & 1 \\
\hline & Citrobacter fruendii & 1 & 0 & 1 \\
\hline & Total & 8 & 0 & 8 \\
\hline
\end{tabular}

\begin{tabular}{|c|c|c|c|c|}
\hline \multicolumn{5}{|c|}{ Organism * Lock solution Cross tabulation in jugular } \\
\hline \multirow{4}{*}{ Organism } & \multicolumn{2}{c|}{ Lock solution(E=Ethanol/ H=heparin) } & \multirow{2}{*}{ Total } \\
\cline { 2 - 5 } & Heparin & Ethanol & \\
\hline \multirow{5}{*}{ Jugular Access } & Staphylococcus aureus & 2 & 0 & 2 \\
\cline { 2 - 5 } & Enterococcus faecalis & 1 & 0 & 1 \\
\cline { 2 - 5 } & $\begin{array}{c}\text { Acinetobacter baumannii- } \\
\text { calcoaceticus Complex }\end{array}$ & 1 & 1 & 2 \\
\cline { 2 - 5 } & Klebsiella pneumonia & 1 & 0 & 1 \\
\cline { 2 - 5 } & Pseudomonas aeruginosa & 1 & 0 & 7 \\
\cline { 2 - 5 } & Total & 6 & 1 & 1 \\
\hline
\end{tabular}
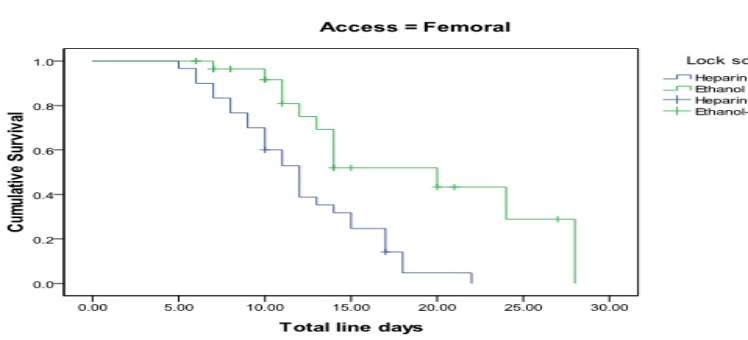

Figure 1 : Survival Analysis of Femoral Access 
Fig. 2 shows in patients with Jugular access, overall comparison of the survival curve of the catheter with respect to the event of CRBSI shows that the curve of the more events in the heparin group and the survival of the ethanol group was longer as compared to the heparin group. This was statistically significant at $95 \%$ confidence interval with Log-Rank Test pvalue 0.000 which is less than 0.05 . The Kaplan Meir survival curve shows difference between the two groups for a period of 60 days, however after that the number of patients with catheter decreased hence it is difficult to comment.

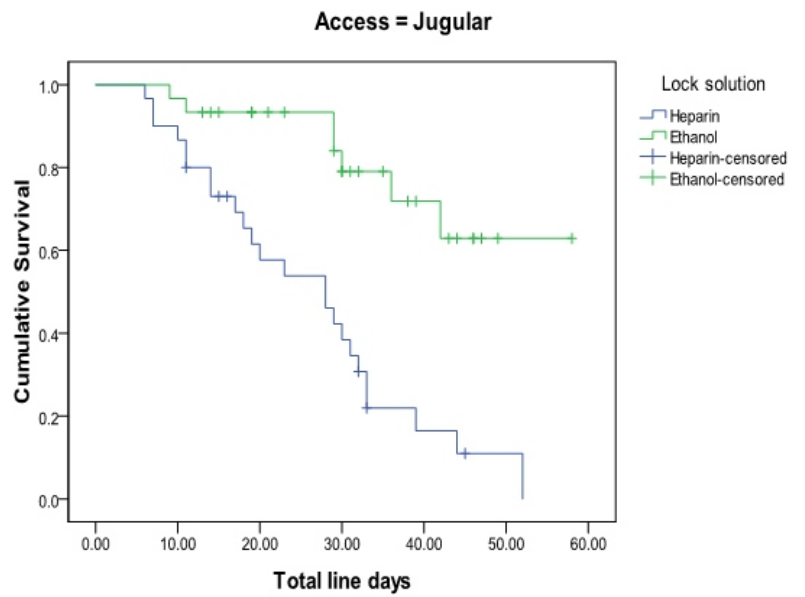

Figure 2 : Survival Analysis of Jugular Access

\begin{tabular}{|l|l|l|l|l|l|l|l|}
\hline \multirow{2}{*}{$\begin{array}{l}\text { Venous } \\
\text { Access }\end{array}$} & \multirow{2}{*}{$\begin{array}{l}\text { Lock Solution/ } \\
\text { Catheter Days }\end{array}$} & & \multicolumn{6}{l}{ Number at Risk (Number of CRBSI) } \\
\cline { 3 - 8 } & & 10 & 20 & 30 & 40 & 50 & 60 \\
\hline \multirow{2}{*}{ Overall } & Heparin & $60(12)$ & $48(26)$ & $17(6)$ & $11(6)$ & $3(1)$ & $1(1)$ \\
\cline { 2 - 8 } & Ethanol & $60(2)$ & $49(9)$ & $28(5)$ & $17(2)$ & $8(1)$ & $1(0)$ \\
\hline \multirow{2}{*}{ Femoral } & Heparin & $30(9)$ & $21(18)$ & $1(1)$ & $0(0)$ & - & - \\
\cline { 2 - 8 } & Ethanol & $30(1)$ & $20(8)$ & $6(3)$ & $0(0)$ & - & - \\
\hline \multirow{2}{*}{ Jugular } & Heparin & $30(3)$ & $27(8)$ & $16(5)$ & $11(6)$ & $3(1)$ & $1(1)$ \\
\cline { 2 - 8 } & Ethanol & $30(1)$ & $29(1)$ & $22(2)$ & $17(2)$ & $8(1)$ & $1(0)$ \\
\hline
\end{tabular}

The numbers in parenthesis in the table below $\mathrm{x}$ axis are the number of patients in whom an episode of CRBSI occurred in the interval between follow-up assessments.

\section{DISCUSSION}

The purpose of this study was to evaluate the impact of concentrated ethanol lock, administered 20 minutes before dialysis initiation, on the rate of CRBSI in non tunneled hemodialysis catheters compared to heparin lock. The main results of the study are that CRBSI occurred with more frequency in heparin group in comparision to ethanol group which is comparable with studies done by Sanders et. $\mathrm{Al}^{20}$ and it occurred later in ethanol group than in heparin group and also many of them were culture negative. However, catheter thrombosis and bleeding from exit site was higher in heparin group. Thus overall catheter loss was higher in heparin group mainly due to infection than thrombosis and uncontrolled bleeding from exit site.Ethanol has both bactericidal and fungicidal properties and development of resistance is not known. ${ }^{13}$ Furthermore, it has been reported that ethanol appears to possess intrinsic anticoagulant activity, as evidenced by the use of ethanol to restore catheter patency ${ }^{15}$ and it is cost-effective.

Heparin is the most commonly used interdialytic lock solution because of its anticoagulant properties; however it lacks antibacterial properties hence not effective in prevention of CRBSI. Ethanol lock therapy has been used successfully in treatment of CRBSI in dialysis population. ${ }^{17,21-23}$ For the above reasons we tried catheter locking with ethanol for prevention ofCRBSI.

The positive finding of this study is that CRBSI occurred with lesser frequency in ethanol groups which echoes with the findings of previous in vivo studies by Mouw et al. ${ }^{24}$, and Sanders et al..$^{20}$ done to evaluate ethanol as a catheter locking solution in non-dialysis setting, where also the incidence of CRBSI decreased. CRBSI occurred later in ethanol group than in heparin group and also many of them were culture negative which coincides with study done by Broom et al. ${ }^{2.5}$

However, in our study we had two incidence of catheter thrombosis with heparin lock compared to use of ethanol as a lock, the reasons may be due to inadequate heparin locking dosage $^{26}$ or leakage ${ }^{27}$ or gravitational loss from catheter lumen into systemic circulation. ${ }^{28}$ Patency of catheter lumen in ethanol lock might be due to

1) Concentration of ethanol An ethanol concentration above $40 \%$ is required to inhibit bacterial growth in established biofilms.54 When instilled into a CVC at a concentration between $40 \%$ and $100 \%$, ethanol has been shown to be rapidly bactericidal and fungicidal in vitro, with no concern for development of resistant organisms. ${ }^{29}$ A major limitation in the use of high concentrated ethanol for interdialytic locking could be the occurrence of catheter dysfunction that might compromise catheter duration or impair HD performance. A study in which $100 \%$ ethanol was used to lock catheter lumens for 24 hours resulted in total occlusion of one out of three catheters. ${ }^{29}$ We choose to use a $70 \%$ ethanol lock solution because this concentration has been shown to be bactericidal in established biofilms and based on previous reports. ${ }^{29,30}$

2) Duration of catheter lock with ethanol Balestrino et a $1^{13}$ state that, a significant 3-log reduction in the number of biofilmassociated gram-positive cocci occurred already after 20 minutes exposure to a $60 \%$ ethanol lock solution. Adwell time of 30 minutes was required for complete eradication in order to kill established biofilms of gram-positive and gramnegative organisms and candida but $\mathrm{Qu} \mathrm{Y}$ et $\mathrm{al}^{31}$ showed that an exposure time of 1 minute to a $70 \%$ ethanol solution was sufficient for the sterilization of a bacterial biofilm.

For the above and practical reasons we tried catheter locking with ethanol 20 minutes prior to initiation of every hemodialysis session for prevention of CRBSI. This was 
decided because a longer dwell time would have interfered too much with patient care. We feel that an effective strategy would be, along with catheter exit site care, to expose catheter lumens to $70 \%$ ethanol for a period of 30 minutes prior to dialysis, which would sterilize the biofilm. The ethanol solution be then withdrawn and followed by a routine dialysis session.

The absence of adverse event in ethanol group might be due to consideration of major limitation in the use of high concentrated ethanol for interdialytic locking, that could have caused catheter dysfunction that might compromise catheter duration or impair HD performance. A study in which $100 \%$ ethanol was used to lock catheter lumens for 24 hours resulted in total occlusion of one out of three catheters. ${ }^{29}$ There are numerous reports in the literature of repeated exposures to concentrated ethanol between 60 and $70 \%$ as a flushing solution and as a lock without impairment of catheter function but the dwell time of ethanol exposure was short and never exceeded 24 hours. ${ }^{15,20,24,25,31-34}$

In our study, the ethanol lock was in place only during $20 \mathrm{~min}$ prior to initiation of every hemodialysis session and post dialysis the lumens were locked with heparin during the interdialytic period (48-72 hours) which may have been the reason for none catheter thrombosis in this group.

Similar to other studies performed in non HD adults and infants in whom ethanol was used for preventing or treating catheter-associated infections, ${ }^{15-17}$ no adverse reactions were reported our study after the instillation of the ethanol lock.

3) Ethanol solution in isolation with anticoagulant effect Citrate solution mixed with higher concentrations $(>30 \%)$ leads to precipitation of citrate and ethanol inactivates heparin solution. Hence we did not consider using concentrated ethanol lock in association with heparin or citrate. Also there were few reports that ethanol has some anticoagulant properties ${ }^{15}$ which tempted us to use ethanol $70 \%$ ethanol in isolation.

Also, heparin locking be done for interdialytic period so that the catheter loss to thrombotic episodes is prevented. However, heparin locking dosage should be adequate ${ }^{26}$ in patients without risk of bleeding as there were increased rate of thrombosis in our patients on heparin lock which occurred as in other study ${ }^{35}$ with used dose heparin lock which might be due to leakage ${ }^{27}$ or gravitational loss. ${ }^{28}$ However further studies are necessary to determine the adequate dose of heparin lock to avoid thrombosis along with minimization of bleeding risk. There was one bleeding from exit site of right internal jugular vein catheterized patient with heparin lock which did not stopped after external compression with adrenaline soaked gauze for 1 hour and this type of complication has been reported in other study.

Thus as such $70 \%$ ethanol may not cause thrombosis when kept for few hours; however prolonged exposure might result in catheter dysfunction. As ethanol lock was kept for 20 mins only in this study, there were no complications as such which correlates with study by Crnich et. al. ${ }^{32}$ where 9 weeks exposure to ethanol had no significant effect on mechanical properties of catheter and study by Landry et. al where 26 weeks exposure to ethanol had no effect on ultrastructure of catheter. ${ }^{37}$ We feel that an effective strategy would be - along with catheter exit site care, exposure of catheter lumens to ethanol $70 \%$ for a period of 30 minutes pre-dialysis would sterilize the biofilm. The ethanol solution be then withdrawn and followed by a routine dialysis sessions.

\section{CONCLUSION}

Using ethanol $70 \%$ as a catheter locking solution, locked for 20 minutes before initiation of every hemodialysis session, is safe and effective compared to heparin lock in prevention of CRBSI

\section{REFERENCES}

1. Kjellstrand CM. The Achilles' heel of the hemodialysis patient. Archives of internal medicine. Jul 1978;138(7):1063-1064. http://dx.doi.org/10.1001/archinte.1978.03630320007003 http://dx.doi.org/10.1001/archinte.138.7.1063 PMid:666461

2. Quinton W, Dillard D, Scribner BH. Cannulation of blood vessels for prolonged hemodialysis. Transactions - American Society for Artificial Internal Organs. Apr 10-11 1960;6:104113.

PMid: 13738750

3. Yoon HE, Chung S, Chung HW, et al. Status of initiating pattern of hemodialysis: a multi-center study. Journal of Korean medical science. Jan 2009;24 Suppl:S102-108. http://dx.doi.org/10.3346/jkms.2009.24.S1.S102 PMid:19194537 PMCid:PMC2633201

4. CORR2015. CORR Annual ReportTreatment of End-Stage Organ Failure in Canada, 2004 to 2013. Ottawa, ON: CIHI; 2015.

5. Huijbregts HJ, Bots ML, Wittens $\mathrm{CH}$, et al. Hemodialysis arteriovenous fistula patency revisited: results of a prospective, multicenter initiative. Clinical journal of the American Society of Nephrology : CJASN. May 2008;3(3):714-719. http://dx.doi.org/10.2215/CJN.02950707 PMid:18256379 PMCid:PMC2386712

6. Raad I, Costerton W, Sabharwal U, Sacilowski M, Anaissie E, Bodey GP. Ultrastructural analysis of indwelling vascular catheters: a quantitative relationship between lumina colonization and duration of placement. The Journal of infectious diseases. 1993;168(2):400-407.

http://dx.doi.org/10.1093/infdis/168.2.400 PMid:8335977 
7. Pradeep Kumar SS, Easwer HV, Maya Nandkumar A. Multiple drug resistant bacterial biofilms on implanted catheters - a reservoir of infection. The Journal of the Association of Physicians of India. Oct 2013;61(10):702-707. PMid:24772725

8. Duguid IG, Evans E, Brown MR, Gilbert P. Effect of biofilm culture upon the susceptibility of Staphylococcus epidermidis to tobramycin. The Journal of antimicrobial chemotherapy. Dec 1992;30(6):803-810. http://dx.doi.org/10.1093/jac/30.6.803 PMid:1289354

9. Allon M. Prophylaxis against dialysis catheter-related bacteremia: a glimmer of hope. American journal of kidney diseases : the official journal of the National Kidney Foundation. 2008;51(2):165-168. http://dx.doi.org/10.1053/j.ajkd.2007.12.003 PMid:18215693

10. Macrae JM, Dojcinovic I, Djurdjev O, et al. Citrate 4\% versus heparin and the reduction of thrombosis study (CHARTS). Clinical journal of the American Society of Nephrol: CJASN. Mar 2008;3(2):369-374.

PMid:18308996 PMCid:PMC2390935

11. Saxena AK, Panhotra BR, Naguib M. Sudden irreversible sensory-neural hearing loss in a patient with diabetes receiving amikacin as an antibiotic-heparin lock. Pharmaco. Jan 2002;22(1):105-108

http://dx.doi.org/10.1592/phco.22.1.105.33507

12. Wolley MJ, Taylor SL, Hossain F, Abbas SA, Marshall MR. Association between antimicrobial locks for hemodialysis central venous catheters and antibiotic resistance. Hemodialysis int. International Sym on Home HD. Oct 2012;16 Suppl 1:S2-9.

13. Balestrino D, Souweine B, Charbonnel N, et al. Eradication of microorganisms embedded in biofilm by an ethanol-based catheter lock solution. Nephrology, dialysis, transplantation : official publication of the European Dialysis and Transplant Association - European Renal Association. Oct 2009;24(10):3204-3209. http://dx.doi.org/10.1093/ndt/gfp187 PMid:19383833

14. Peters BM, Ward RM, Rane HS, Lee SA, Noverr MC. Efficacy of ethanol against Candida albicans and Staphylococcus aureus polymicrobial biofilms. Antimicrobial agents and chemotherapy. Jan 2013;57(1):74-82.

http://dx.doi.org/10.1128/AAC.01599-12 PMid:23070170 PMCid:PMC3535989

15. Pennington CR, Pithie AD. Ethanol lock in the management of catheter occlusion. JPEN. Journal of parenteral and enteral nutrition. Sep-Oct 1987;11(5):507-508.

16. Marr KA, Sexton DJ, Conlon PJ, Corey GR, Schwab SJ, Kirkland KB. Catheter-related bacteremia and outcome of attempted catheter salvage in patients undergoing hemodialysis. Ann Intern Med. Aug 15 1997;127(4):275-280.

17. KubiakDW, Gilmore ET, Buckley MW, Lynch R, Marty FM, Koo $S$. Adjunctive management of central line-associated bloodstream infections with $70 \%$ ethanol-lock therapy. The Journal of antimicrobial chemo. Jun 2014;69(6):1665-1668.

18. Vascular Access Work G. Clinical practice guidelines for vascular access. Am J Kidney Dis. Jul 2006;48 Suppl 1:S248273. http://dx.doi.org/10.1053/j.ajkd.2006.04.040 PMid:16813991

19. Mermel LA, Allon M, Bouza E, et al. Clinical practice guidelines for the diagnosis and management of intravascular catheter- related infection: 2009 Update by the Infectious Diseases Society of America. Clinical infectious diseases : an official publication of the Infectious Diseases Society of America. 2009;49(1):1-45.

http://dx.doi.org/10.1086/599376

PMid:19489710 PMCid:PMC4039170

20. Sanders J, Pithie A, Ganly P, et al. A prospective double-blind randomized trial comparing intraluminal ethanol with heparinized saline for the prevention of catheter-associated bloodstream infection in immunosuppressed haematology patients. The Journal of antimicrobial chemotherapy. Oct 2008;62(4):809-815. http://dx.doi.org/10.1093/jac/dkn284 PMid:18621987

21. Ackoundou-N'guessan C, Heng AE, Guenu S, et al. Ethanol lock solution as an adjunct treatment for preventing recurrent catheter-related sepsis--first case report in dialysis settingn.NDT. Nov2006;21(11):3339-3340. PMid:16854845

22. Schwab SJ, Weiss MA, Rushton F, et al. Multicenter clinical trial results with the LifeSite hemodialysis access system. Kidney international. 2002;62(3):1026-1033.

23. Khosroshahi HT, Mahdipur H, Parkhideh S, Basmenji S, Khalilzadeh M, Tozihi M. The effectiveness of systemic antibiotic therapy with and without ethanol-locked solution in the treatment of hemodialysis-related catheter infection. SJKDT. May-Jun 2015;26(3):477-481.

24. Mouw E, Chessman K, Lesher A, Tagge E. Use of an ethanol lock to prevent catheter-related infections in children with short bowel syndrome. Journal of pediatric surgery. 2008;43(6):1025-1029.

25. Broom JK, Krishnasamy R, Hawley CM, Playford EG, Johnson $D W$. A randomised controlled trial of Heparin versus EthAnol Lock THerapY for the prevention of Catheter Associated infecTion in Haemodialysis patients--the HEALTHY-CATH trial. BMC nephrology. 2012;13:146.

26. Ivan DM, Smith T, Allon M. Does the heparin lock concentration affect hemodialysis catheter patency? Clinical journal of the American Society of Nephrology : CJASN. Aug 2010;5(8):1458-1462.

27. Markota I, Markota D, Tomic M. Measuring of the heparin leakage into the circulation from central venous catheters--an

in vivo study. Nephrology, dialysis, transplantation : official publication of the European Dialysis and Transplant Association - European Renal Association. May 2009;24(5):1550-1553 
28. Polaschegg HD. Loss of catheter locking solution caused by fluid density. ASAIO journal. May-Jun 2005;51(3):230-235.

29. Metcalf SCL, Chambers ST, Pithie AD. Use of ethanol locks to prevent recurrent central line sepsis. The Journal of infection. 2004;49(1):20-22

30. Opilla MT, Kirby DF, Edmond MB. Use of ethanol lock therapy to reduce the incidence of catheter-related bloodstream infections in home parenteral nutrition patients. JPEN. Journal of parenteral and enteral nutrition. 2007;31(4):302-305.

31. Qu Y, Istivan TS, Daley AJ, Rouch DA, Deighton MA. Comparison of various antimicrobial agents as catheter lock solutions: preference for ethanol in eradication of coagulasenegative staphylococcal biofilms. Journal of medical microbiology. 2009;58(Pt4):442-450.

32. Crnich CJ, Halfmann JA, Crone WC, Maki DG. The effects of prolonged ethanol exposure on the mechanical properties of polyurethane and silicone catheters used for intravascular access. Infect Control Hosp Epidemiol. Aug 2005;26(8):708714.
33 Dannenberg $C$, Bierbach $U$, Rothe A, Beer J, Körholz D. Ethanol-lock technique in the treatment of bloodstream infections in pediatric oncology patients with broviac catheter Journal of pediatric hematology/oncology. 2003;25(8):616621.

34. Onland W, Shin CE, Fustar S, Rushing T, Wong W-Y. Ethanollock technique for persistent bacteremia of long-term intravascular devices in pediatric patients. Archives of pediatrics \& adolescent medicine. 2006;160(10):1049-1053.

35. Lavainne F, Meffray E, Pepper RJ, et al. Heparin use during dialysis sessions induces an increase in the antiangiogenic factor soluble Flt1. NDT - European Renal Association. Jun 2014;29(6):1225-1231

36. Bevc S, Pecovnik-Balon B, Ekart R, Hojs R. Non-insertionrelated complications of central venous catheterizationtemporary vascular access for hemodialysis. Renal failure. 2007;29(1):91-95

37. Landry DL, Jaber RA, Hanumanthappa $N$, et al. Effects of prolonged ethanol lock exposure to carbothane- and siliconebased hemodialysis catheters: a 26-week study. The journal of vascular access. May 29 2015;0(0):0. 